\title{
Desain Peralatan Memasak Untuk Anak Usia 5 Tahun ke Atas sebagai Edukasi Makanan Sehat
}

\author{
Bunga Asgiani Aziza dan Eri Naharani Ustazah \\ Departemen Desain Produk Industri, Fakultas Teknik Sipil dan Perencanaan, \\ Institut Teknologi Sepuluh Nopember (ITS) \\ e-mail: naharani@prodes.its.ac.id
}

\begin{abstract}
Abstrak-Obesitas yang terjadi pada anak usia dini dapat menimbulkan potensi munculnya berbagai penyakit degeneratif hingga berujung pada kematian. Oleh karena itu, perlu adanya edukasi tentang makanan sehat untuk menanggulangi permasalahan obesitas tersebut. Penanaman pendidikan tentang makanan sehat pada anak sejak dini bisa dilakukan melalui kegiatan memasak bersama. Keamanan, kenyamanan, penerapan edukasi tentang makanan sehat, hingga proses pembersihan merupakan permasalahan dan kebutuhan yang perlu diperhatikan dalam kegiatan memasak bersama anak. Pada kebutuhan ini, penulis mencoba memberikan solusi berupa desain peralatan memasak yang berfokus pada edukasi pengolahan makanan sehat. Selain itu peralatan memasak dirancang agar aman digunakan oleh anak. Metode perancangan dilakukan dengan observasi langsung percobaan memasak dengan anak dan dilakukan dengan usability test prototip produk pada anak untuk pengembangan desain. Pengamatan pada user dilakukan dengan metode shadowing dan usability test. Dari metode shadowing tersebut didapatkan hasil analisa permasalahan dan kebutuhan yang dirangkum dalam Affinity Diagram hingga ditemukan konsep perancangan yang berhubungan dengan fitur yang ditawarkan pada perancangan ini. Desain peralatan memasak berkonsep edukasi makanan sehat ini bertujuan untuk memfasilitasi pengolahan sayur dan buah sekaligus mengedukasi anak untuk mengonsumsi makanan sehat. Hasil dari perancangan meliputi peralatan memasak, di antaranya pisau, peeler, cetakan buah, melon baller, spatula, Alat tumbuk, dan Alas potong, sesuai dengan kebutuhan mengolah buah dan sayur.
\end{abstract}

Kata kunci: peralatan memasak, edukasi makanan sehat, anak

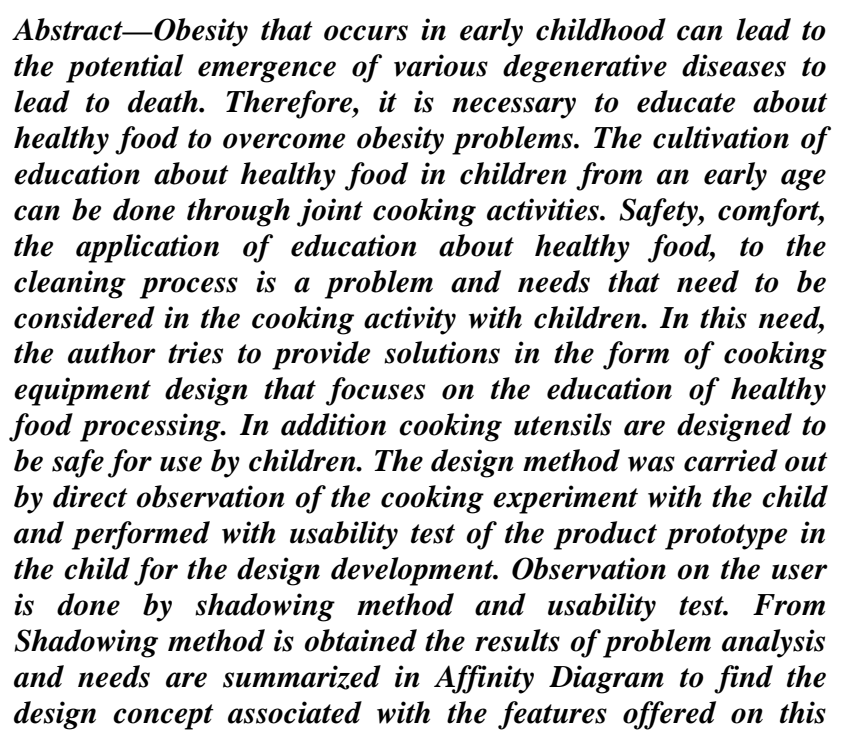

Abstract-Obesity that occurs in early childhood can lead to the potential emergence of various degenerative diseases to lead to death. Therefore, it is necessary to educate about healthy food to overcome obesity problems. The cultivation of education about healthy food in children from an early age can be done through joint cooking activities. Safety, comfort, the application of education about healthy food, to the cleaning process is a problem and needs that need to be considered in the cooking activity with children. In this need, the author tries to provide solutions in the form of cooking equipment design that focuses on the education of healthy food processing. In addition cooking utensils are designed to be safe for use by children. The design method was carried out by direct observation of the cooking experiment with the child and performed with usability test of the product prototype in the child for the design development. Observation on the user is done by shadowing method and usability test. From Shadowing method is obtained the results of problem analysis design concept associated with the features offered on this design. The design of cooking equipment conceptual education of healthy food aims to facilitate the processing of vegetables and fruits as well as educate children to eat healthy food. The results of the design include cooking utensils for example, knives, peeler, fruit molds, melon baller, spatula, cutting, mortar and pestle, in accordance with the needs of processing fruits and vegetables.

Keywords: cooking equipment, helthy food education, children

\section{PENDAHULUAN}

Pada era modern saat ini, keberadaan makanan cepat saji atau biasa disebut fast food sangat marak di seluruh dunia. Kelezatan dan kepopuleran fast food, juga membawa dampak pada gaya hidup masyarakat dari hanya sekadar mencoba hingga menjadi makanan yang dikonsumsi sehari-hari. Padahal, mengonsumsi fast food secara berlebihan dapat menyebabkan overweight (kelebihan berat badan) dan obesitas yang dapat mengancam kesehatan individu. Hal ini dikarenakan kandungan kalori, sodium, gula, dan lemak yang cukup tinggi dalam fast food. Dari sebuah penelitian, ditemukan adanya hubungan positif antar konsumsi fast food dengan overweight dan obesitas [1].

Salah satu kelompok umur yang beresiko terjadinya overweight dan obesitas adalah kelompok anak. Obesitas dapat muncul kapan saja namun lebih sering terjadi pada tahun pertama usia kehidupan, usia 5-6 tahun dan selama masa remaja. Kegemukan pada anak mengalami peningkatan dari tahun ke tahun di seluruh dunia. Menurut WHO (2006), pada tahun 2013 sekurang-kurangnya ada 42 juta anak berusia di bawah 5 tahun mengalami kegemukan. Peningkatan prevalensi kegemukan tidak hanya saja terjadi pada negara yang berpendapat anti tetapi juga terjadi pada negara berpendapatan sedang dan rendah terutama di daerah perkotaan. Data dari survey The National Health and Nutrition Examination Survey (NHANES) pada tahun 2009 menunjukkan bahwa prevalensi kegemukan pada anak telah meningkat, yaitu dari 5,0\% menjadi $12,4 \%$ untuk anak-anak usia 2-5 tahun. Di Indonesia sendiri peningkatan angka obesitas juga terjadi. Menurut data Riskesdas pada tahun 2010 terjadi peningkatan prevalensi obesitas dari 12,2\% pada tahun 2007 menjadi 14,0 pada tahun 2010. Bila obesitas timbul pada masa kanak-kanak kemudian berlanjut sampai dewasa, cenderung sulit untuk diatasi. Obesitas yang menetap hingga dewasa akan berhubungan dengan penyakit degeneratif seperti hipertensi, penyakit diabetes, jantung koroner, liver, kantung empedu, dan berujung pada kematian. Sebagai upaya mengurangi prevalensi obesitas pada anak, badan kesehatan dunia atau WHO, menghimbau agar keluarga terutama orang tua lebih pintar dan cermat dalam memilih makanan yang sehat bagi anak-anaknya. Hal ini disebabkan karena preferensi atau kecenderungan untuk menyukai makanan tertentu dibentuk sejak awal masa kanak-kanak dan saat ini orang tua-lah yang menjadi pengambil keputusan terpenting. Kesehatan dan gizi merupakan aspek penting dalam proses tumbuh kembang anak karena pemberian makanan yang sehat akan mempengaruhi 
perkembangan kognitif anak selanjutnya. Oleh karena itu, diperlukan pengasuhan yang tepat untuk menanamkan kebiasaan makanan sehat secara beragam.

Perlu dilakukan upaya pencegahan dan penanggulangan faktor risiko obesitas dengan menanamkan pendidikan kesehatan pada anak sejak usia dini, melalui peningkatan komunikasi, informasi dan edukasi (KIE), seperti gerakan anti rokok, gerakan cinta serat (sayur dan buah) serta membudayakan aktivitas fisik. Dalam proses pembelajaran anak tentang makanan sehat, partisipasi dari baik dari keluarga dan lingkungan sekitar seperti lingkungan sekolah sangat berpengaruh. Juga diperlukan metode yang menarik bagi anak dan kreatifitas yang tinggi bagi orang tua dan guru untuk memperkenalkan mereka pada makanan sehat, salah satunya adalah dengan memasak bersama. Berdasarkan penelitan oleh Dewi dan Ratna ditemukan bahwa kegiatan memasak bersamaan akan dapat secara efektif meningkatkan pengetahuan anak tentang makanan sehat [2].

Dalam rangka memerangi obesitas, di Amerika sendiri sudah mulai banyak diterapkan program memasak makanan sehat di rumah, seperti Supplemental Nutrition Assistance Program (SNAP), yaitu program yang mendorong untuk hidup sehat dengan cara meningkatkan konsumsi sayur dan buahbuahan melalui cara memasak bersama [3, 4 dan 5].

Dalam kegiatan memasak bersama anak, tentunya dibutuhkan peralatan memasak yang dapat menunjang aktifitas memasak dengan baik. Namun dalam aktivitas memasak saat ini dapat dianalisa bahwa peralatan memasak yang digunakan merupakan peralatan memasak untuk orang dewasa, sehingga kadang anak kesulitan saat memegang atau menggenggam karena ukurannya yang terlalu besar. Peralatan memasak yang digunakan juga menggunakan material yang kurang aman untuk anak, sehingga anak perlu diberi wawasan tentang bagian yang harus dan tidak harus digenggam saat digunakan. Selain itu, anak memiliki karakter yang tergesa-gesa dan cenderung menimbulkan resiko kecelakaan seperti terjatuh dan terluka. Oleh karena itu, dibutuhkan peralatan masak yang sesuai dan dapat menunjang kegiatan memasak untuk anak sekaligus dapat mengedukasi mereka tentang konsumsi makanan sehat sejak dini $[6,7]$.

\section{METODE PENELITIAN}

\section{A. Tahap Pengambilan Data}

Metode pengambilan data diperoleh dari pengumpulan data primer melalui deep interview dengan orang tua anak dan guru TK untuk mengetahui karakter, kecenderungan, hingga pola interaksi anak dalam aktifitasnya sehari-hari. Namun untuk melakukan obesrvasi lebih mendalam lagi, dilakukan observasi secara langsung melalui metode shadowing dengan mengikuti kegiatan anak selama satu periode aktifitas. Penulis melakukan untuk mengetahui permasalahan dan kebutuhan anak saat melakukan berbagai aktifitas serta kecenderungan karakternya. Sedangkan data sekunder diperoleh dari literatur berupa jurnal dan data dari internet seputar perkembangan anak, peralatan masak, material yang digunakan, hingga proses produksinya.

\section{B. Tahap Studi dan Analisa}

Tahapan studi dan analisa meliputi bagaimana merancang peralatan memasak untuk anak yang aman digunakan, dan dapat memfasilitasi pembersihan lokasi yang efektif hingga penyimpanan peralatan setelah pemakaian [8]. Berikut ini adalah tahapan studi dan analisa yang telah dilakukan:
1. Analisa positioning

Untuk menganalisis fitur dan harga produk sejenis yang sudah ada di pasaran, untuk dapat dibandingkan dan ditemukan harga dan fitur yang sesuai untuk target pasar.

2. Studi aktivitas anak

Studi ini dilakukan untuk mengetahui pola interaksi dan kecenderungan anak usia 5 tahun ke atas dalam aktifitas sehari-hari. Sehingga dapat diketahui kebutuhan pengguna dan dapat menghasilkan alternatif fitur yang sesuai dengan kebutuhan pengguna.

3. Analisa ergonomi

Dilakukan dengan mengukur 10 tangan anak melalui media plastisin yang digenggam sehingga diketahui anthropometri tangan anak (Gambar 1).

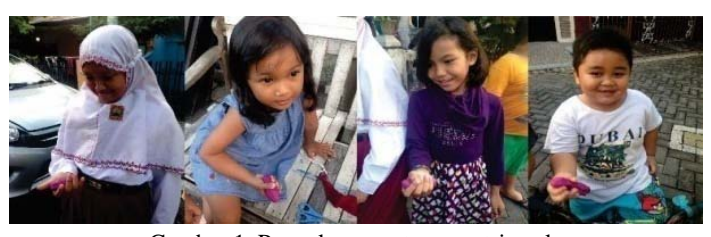

Gambar 1. Pengukuran antropometri anak

Dari pengukuran antropometri tangan anak di atas, Tabel 1 menunjukkan hasil pengukuran dari analisa ergonomi anak:

Tabel 1. Data Antropometri tangan anak hasil pengukuran

\begin{tabular}{|l|c|c|c|}
\hline \multicolumn{1}{|c|}{ Nama/umur } & diameter & panjang & lebar \\
\hline Arjuna (8) & $32 \mathrm{~mm}$ & $40 \mathrm{~mm}$ & $30 \mathrm{~mm}$ \\
\hline Rio (8) & $31 \mathrm{~mm}$ & $40 \mathrm{~mm}$ & $30 \mathrm{~mm}$ \\
\hline Irul (5) & $28 \mathrm{~mm}$ & $35 \mathrm{~mm}$ & $25 \mathrm{~mm}$ \\
\hline Kesha (10) & $32 \mathrm{~mm}$ & $40 \mathrm{~mm}$ & $32 \mathrm{~mm}$ \\
\hline Bilqis (10) & $33 \mathrm{~mm}$ & $42 \mathrm{~mm}$ & $31 \mathrm{~mm}$ \\
\hline Azka (8) & $30 \mathrm{~mm}$ & $39 \mathrm{~mm}$ & $28 \mathrm{~mm}$ \\
\hline Naura (7) & $31 \mathrm{~mm}$ & $39 \mathrm{~mm}$ & $29 \mathrm{~mm}$ \\
\hline Ardo (6) & $30 \mathrm{~mm}$ & $38 \mathrm{~mm}$ & $29 \mathrm{~mm}$ \\
\hline Shafa (5) & $26 \mathrm{~mm}$ & $35 \mathrm{~mm}$ & $25 \mathrm{~mm}$ \\
\hline Najwa (10) & $32 \mathrm{~mm}$ & $40 \mathrm{~mm}$ & $30 \mathrm{~mm}$ \\
\hline
\end{tabular}

Data anthropometri tersebut digunakan untuk menjadi acuan ukuran dan bentuk handle yang sesuai dengan anak.

4. Analisa kebutuhan peralatan memasak.

Dilakukan untuk menemukan batasan peralatan memasak yang dirancang untuk memasak makanan sehat.

5. Analisa pencarian bentuk

Mengembangkan konsep dan fitur hingga ditemukan alternatif bentuk untuk dilakukan usability test.

6. Analisa usability test

Dilakukan dengan cara mencobakan beberapa alternatif bentuk peralatan memasak secara langsung kepada anak untuk mengetahui pemahaman bentuk, kecenderungan excitement, serta faktor keamanan saat digunakan.

7. Analisa tekstur

Dilakukan untuk menentukan bagian yang diberi material antislip pada handle sehingga dapat meningkatkan keamanan penggunaan.

8. Analisa pencarian image produk

Dilakukan melalui analisa persona anak, untuk mengetahui permainan seperti apa yang mereka inginkan, lalu dibuat image board untuk mengetahui style dan kesan yang ingin ditampilkan pada produk peralatan memasak.

9. Analisa warna

Untuk mengetahui warna yang dipilih dengan psikologis warna yang sesuai untuk digunakan oleh anak. 


\section{Analisa material}

Diperlukan untuk mengetahui material untuk digunakan pada perancangan peralatan memasak dengan menggunakan matriks sifat, kelebihan dan kekurangan jenis material.

11. Analisa branding

Diperlukan sebagai dasar identitas produk, meliputi pemilihan nama merek, pembuatan logo, hingga desain packaging dan buku memasak untuk anak.

12. Studi teknik produksi

Diperlukan untuk mengetahui proses produksi dari penggunaan material plastik, yaitu material utama yang digunakan pada perancangan ini.

Batasan permasalahan pada desain adalah:

1. Mendesain 1 (satu) set peralatan memasak untuk anak usia 5 (lima) tahun ke atas sebagai edukasi makanan sehat.

2. Subjek perancangan adalah anak usia 5 tahun ke atas dengan kemampuan finansial menengah ke atas.

3. Desain peralatan memasak yang mengakomodasi kegiatan memasak sayuran dan buah, meliputi alas potong, pisau, peeler, spatula, melon baller, cetakan buah dan alat tumbuk.

4. Desain peralatan memasak yang dapat mengakomodasi sistem pembersihan yang mudah.

5. Mendesain packaging berupa tas yang dapat memfasilitasi penyimpanan yang mudah setelah pemakaian.

6. Mendesain buku memasak untuk mengedukasi tentang makanan sehat.

\section{HASIL DAN PEMBAHASAN}

\section{A. Konsep Perancangan}

Konsep desain ditentukan berdasarkan permasalahan yang ada secara langsung. Dari analisa yang telah dilakukan, didapatkan konsep perancangan peralatan memasak untuk anak dengan konsep desain, di antaranya: proses memasak sehat, compact, creative, safety dan simple cleaning. Kesan yang ingin ditunjukkan dalam style perancangan produk ini adalah playful friendly dan safe yang sesuai dengan karakter permainan yang disukai oleh anak. Konsep yang diangkat pada perancangan ini adalah:

1. Proses memasak sehat: Yang dimaksud dengan konsep proses memasak sehat adalah peralatan memasak untuk anak yang dapat memfasilitasi kegiatan pengolahan makanan sehat seperti sayur dan buah, jadi semua peralatan dirancang khusus untuk mengolah buah-buahan dan sayuran.

2. Creative: Yang dimaksudkan dengan konsep kreatif di sini adalah bagaimana produk ini dapat menstimuli kreatifitas anak, salah satunya melalui eksplorasi pola potong buahbuahan. Untuk memfasilitasi kreatifitas anak, ditambahkan fitur cetakan buah dengan bentuk dasar yang dapat disusun sesuai kreatifitas anak

3. Safety: Fitur safety di sini dimaksudkan untuk memfasilitasi ergonomi yang sesuai untuk tangan anak dan keamanan saat pengoperasian. Konsep safety di sini dikembangkan dengan menambahkan fitur antislip pada setiap handle peralatan untuk mengantisipasi kecelakaan yang disebabkan oleh tangan tergelicir saat pengoperasian. Fitur antislip terdiri atas 3 tombol (button) berwarna kuning yang berada pada bagian utama handle yang digenggam saat pengoperasian. 3 tombol berwarna kuning ini merupakan batasan bagian yang harus digenggam anak, yang nantinya akan diberi material plastik anti slip.

4. Simple cleaning: Konsep easy cleaning di sini memfasilitasi pembersihan yang memudahkan baik dari orang tua maupun anak. Untuk memfasilitasi fitur pembersihan yang mudah produk ini dilengkapi dengan storage pembuangan sampah yang terletak pada talenan, sehingga sampah mudah dikumpulkan dan langsung bisa dibuang ke tempat sampah.

\section{B. Tahap Studi Model}

Tahap studi model meliputi pembuatan model perancangan handtools. Dibuat 2 (dua) kali percobaan pembuatan model untuk digunakan pada usability test. Pada pembuatan studi model yang pertama digunakan material clay untuk memahami kenyamanan penggunaan. Sedangkan studi model yang kedua menggunakan material kayu yang sudah dilengkapi dengan mata pisau sehingga sudah bisa diaplikasikan langsung terhadap bahan makanan (Gambar-gambar 2 dan 3). Berikut adalah tahap studi model yang sudah dilakukan:

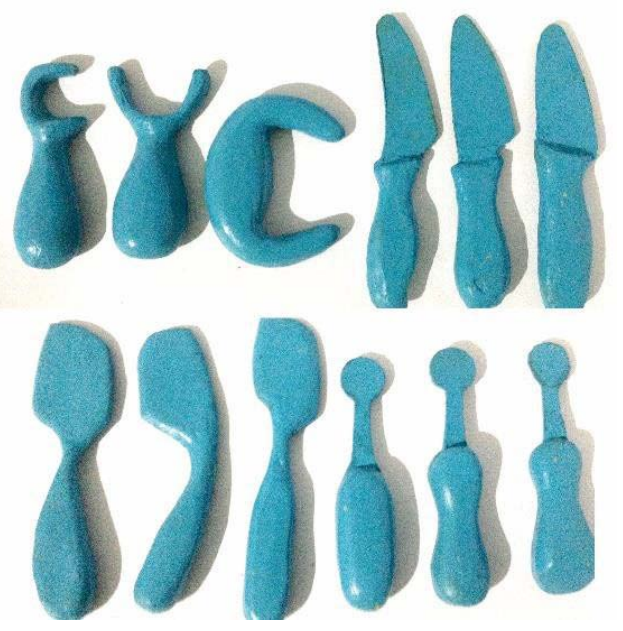

Gambar 2. Studi model dengan bahan clay

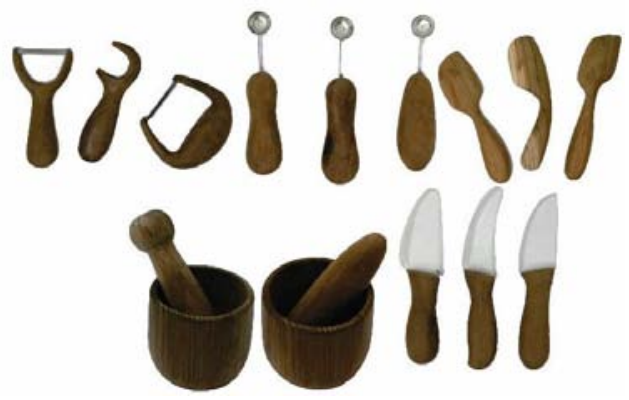

Gambar 3. Studi model dengan material kayu

\section{Tahap Usability Test}

Tahap usability test meliputi:

1. Usability test pertama: penulis meneliti bagaimana reaksi anak saat menggunakan mock-up dari handle kitchen tools, diukur dari parameter pemahaman penggunaan, kenyamanan saat digunakan dan ketertarikan bentuk (Gambar 4). Masing-masing dari 1 jenis kitchen tools ada 3 alternatif bentuk. Alternatif mock-up dibuat berdasarkan anthropometri tangan anak. Setelah membuat mock-up penulis menganalisa pemakaiannya oleh anak-anak.

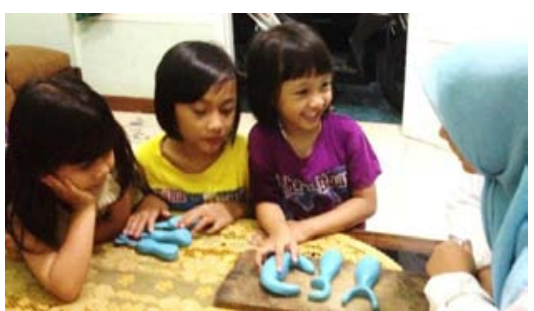

Gambar 4. Usability test pertama 
2. Usability test kedua: Di sini penulis meneliti bagaimana ketika anak menggunakan kitchen tools secara langsung. Pada Usability test kedua mock-up yang berupa kayu sudah bisa dioperasikan secara langsung pada obyek makanan seperti buah dan sayur. Mock-up yang dibuat berupa 6 jenis kitchen tools yaitu pisau, peeler, melon baller, spatula dan alat tumbuk (Gambar 5).

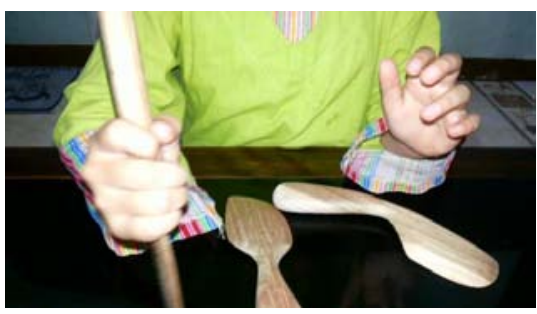

Gambar 5. Usability test kedua

Dari kedua proses analisa usability test yang telah dilakukan penulis, ditemukan bentuk bentuk yang sesuai dengan kriteria keamanan dan kenyamanan untuk anak. Alternatif handle terpilih yang digunakan untuk acuan bentuk desain melonballer, pisau, spatula, dan peeler. Bentuk-bentuk terpilih di atas kemudian dikembangkan lagi dengan berbagai analisa yang dilakukan penulis demi tercapainya konsep yang diinginkan.

\section{Desain final}

Melalui berbagai analisa yang telah penulis lakukan, ditemukan konsep final desain satu set peralatan memasak untuk anak sebagai (Gambar-gambar 6 dan 7).

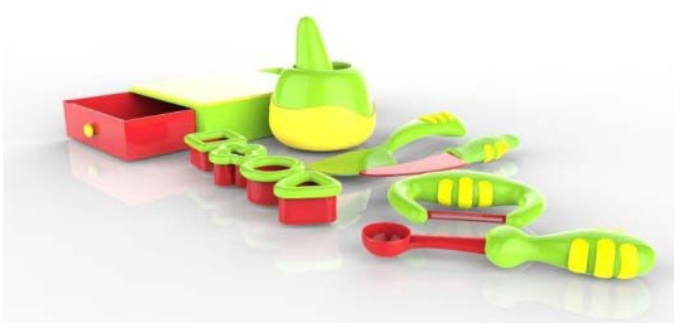

Gambar 6. Desain final

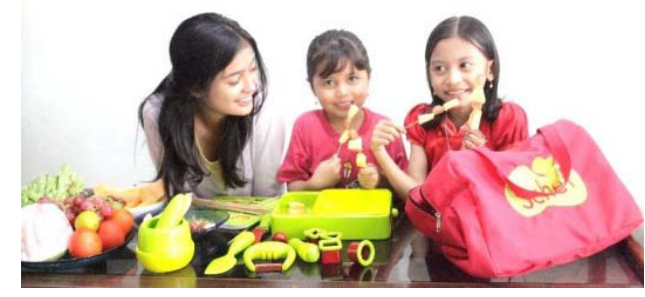

Gambar 7. Percobaan produk desain final

Dalam satu set peralatan memasak terdapat pisau, peeler, melonballer, spatula, alat tumbuk, alas potong dan 4 buah cetakan. Bentuk-bentuk peralatan memasak tersebut didapatkan dari observasi langsung melalui metode usability test terhadap beberapa anak.

\section{E. Tahap Branding}

\section{Desain logo}

Schef berasal dari kata small chef yang berarti koki cilik. Koki cilik memiliki makna perkerjaan sebagai juru masa. Sesuai dengan tujuan utama dari perancangan produk ini yaitu untuk mengedukasi anak tentang makanan sehat melalui kegiatan memasak bersama [9]. Betuk dasar logo diambil dari gambar topi koki yang sangat identic dengan kegiatan memasak. Gambar 8 adalah logo dari brand peralatan masak ini.

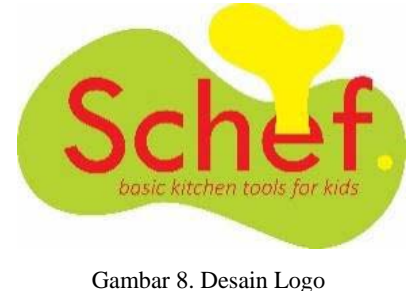

\section{Desain buku}

Dalam satu set peralatan memasak juga dilengkapi dengan buku panduan memasak yang meliputi berbagai macam pengetahuan memasak di dapur yang didesain dengan grafis yang disukai anak meliputi: Edukasi untuk Mengonsumsi Sayur Dan Buah, Perkenalan Bahan Makanan, Peraturan di Dapur, Cara penggunaan peralatan memasak, hingga resep masakan (Gambar 9).

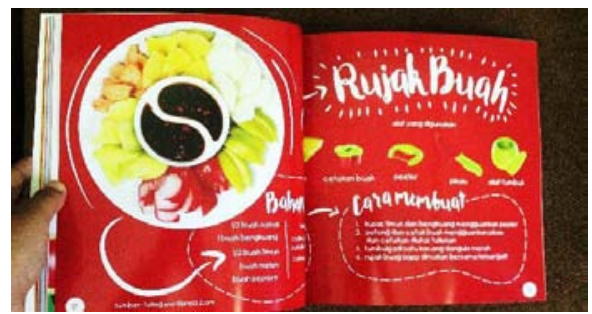

Gambar 9. Buku panduan memasak

3. Desain tas penyimpanan

Dalam memfasilitasi penyimpanan yang mudah, juga didesain tas penyimpanan (Gambar 10). Tas penyimpanan ini dapat menyimpan seluruh elemen dalam satu set agar penyimpanannya lebih terorganisir dengan baik dan tidak terpisah, tas penyimpanan ini memiliki fitur sekat pemisah yang membuat penyimpanan masing-masing alat menjadi semakin terorganisir.

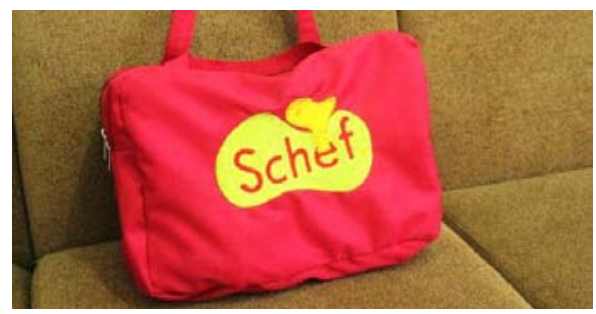

Gambar 10. Tas penyimpanan

\section{F. Pengembangan Desain}

Dalam keberlanjutan produk ini dilakukan pengembangan lineup dan varian produk demi meningkatkan minat terhadap calon konsumen. Pengembangan dari produk ini adalah perancangan varian set dengan tema dan material yang berbeda. Berikut adalah gambaran tentang varian bentuk dan material dari produk ini (Gambar-gambar 11 dan 12). 

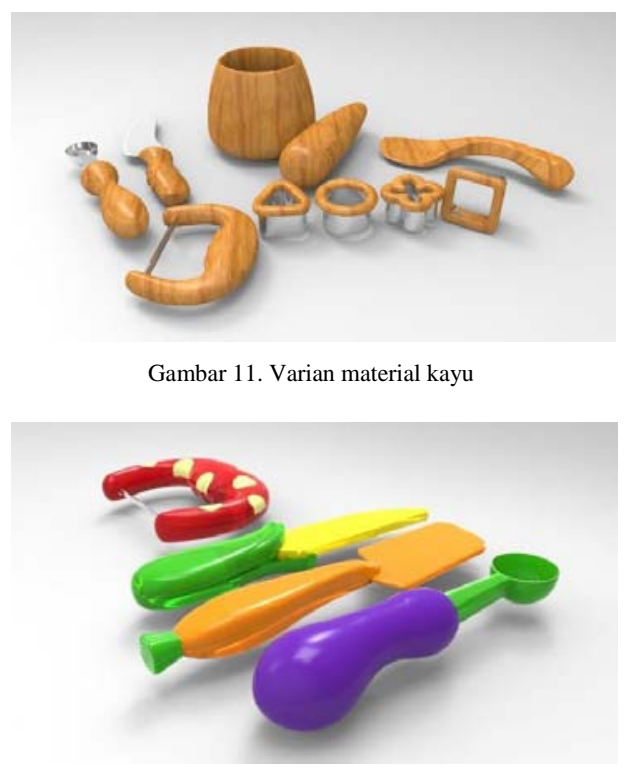

Gambar 12. Varian tema sayuran

\section{KESIMPULAN}

Kesimpulan:

1. Mempelajari kebutuhan desain untuk anak, meliputi pola interaksi, alternatif permainan, benda dan warna yang menarik bagi anak, serta mengetahui kebutuhan saat kegiatan memasak sehingga dapat menjadi dasar untuk mendesain peralatan memasak.

2. Telah dirancang peralatan memasak untuk anak usia 5 tahun ke atas sebagai edukasi makanan sehat dengan konsep proses memasak sehat, safety, creative, compact, dan easy cleaning.

3. Untuk memfasilitasi konsep proses memasak sehat peralatan memasak dirancang khusus untuk mengolah sayuran dan buah serta dilengkapi dengan buku yang berisi tentang edukasi makanan sehat dan resep olahan sayur dan buah yang mudah dan menyenangkan.

4. Sebagai pengembangan konsep safety, ukuran handle peralatan memasak harus sesuai dengan anthropometry tangan anak, selain itu, ditambahkan fitur material antislip pada handle dan fitur stopper pada pangkal handle sehingga tangan anak tidak bersentuhan langsung dengan mata pisau.

5. Untuk memfasilitasi konsep creative, dirancang cetakan buah dengan pilihan bentuk dasar sehingga dapat menstimuli anak untuk berkreasi dengan pola potongan bahan menjadi bentuk baru yang menarik

6. Konsep compact dikembangkan melalui fasilitas penyimpanan yang organize dan mudah dioperasikan berupa tas dengan fitur sekat yang dapat mengorganisir penyimpanan peralatan memasak yang telah selesai dipakai

7. Untuk mengatasi masalah pembersihan setelah memasak dikembangkan konsep easy cleaning. Konsep ini memfasilitasi sistem pembersihan yang mudah melalui fitur storage bahan sisa yang berfungsi sebagai tempat pembuangan yang praktis [10].

Saran:

1. Pengembangan ke depannya membuat varian dengan bentuk dan warna buah-buahan yang disukai anak.

2. Mengembangkan permodelan yang terinspirasi dari bentuk buah-buahan dan sayuran sehingga disukai anak-anak.
Misalnya membuat varian dengan tema peralatan memasak buah-buahan.

3. Mencari alternatif tekstur selain menggunakan material plastik anti slip.

4. Optimalisasi pemanfaatan media sosial sebagai pemasaran produk.

\section{DAFTAR PUSTAKA}

[1] Bowman, Shanthy A., Vinyard, Bryan T. 2004. Fast Food Consumption of U.S. Adults: Impact on Energy and Nutrient Intakes and Overweight Status. Journal of the American College of Nutrition 163-168.

[2] Dewi Nurchayati, Ratna Wahyu Pusari. (2014).Upaya Meningkatkan Pengetahuan Makanan Sehat Melalui Penerapan Sentra Cooking Pada Kelompok Bermain B Di PAUD Baitus Shibyaan Kecamatan Bergas Kabupaten Semarang Tahun Ajaran 2014/2015

[3] Sartika, Ratu Ayu Dewi. 2011. Faktor Risiko Obesitas Pada Anak 5-15 Tahun di Indonesia 2. journal.ui.ac.id/index.php/health/article/download/796/758.

[4] Simatupang, M. Romauli. 2008. Pengaruh Pola Konsumsi, Aktivitas Fisik, dan Keturunan Terhadap Kejadian Obesitas Pada Siswa Sekolah Dasar Swasta di Kecamatan Medan Baru Kota Medan. Diakses dari http://repository.usu.ac.id/bitstream/123456789/6796/1/09 E01346.pdf.

[5] Siti Nurul Hidayati, Rudi Irawan, Boerhan Hidayat. 2003. Obesitas Pada Anak. Diakses dari http://old.pediatrik.com/buletin/06224113652-048qwc.pdf.

[6] Bella Martin, Bruce Hanington. 2012. Universal Method of Design: 100 Way to Research Complex Problems, Develop Innovative Ideas, And Design Effective Solutions. United States of America: Rockport Publisher.

[7] Noviarni, Sri. 2016. Edukasi Anak Dengan Memasak. 0902. Diakses 20 Maret 2016. http://www.koransindo.com/news.php?r=4\&n=4\&date=2016-02-09.

[8] Hanum, T., Dewi, A.P. (2014). Hubungan Antara Pengetahuan dan Kebiasaan Mengkonsumsi Fast Food dengan Status Gizi Pada Remaja http://jom.unri.ac.id/index.php/JOMPSIK/article/viewFile/ 5180/5060

[9] Lilis Puspitosari, S.P (2010) Pengaruh Warna Dapat Membantu Proses Pembelajaran Anak Usia Dini http://kbalnaba.blogspot.co.id/2010/07/pengaruhwarna-dapat-membantu-proses.html

[10] Nusa, A.F.A., Adi, A.C. (2012). Hubungan Faktor Perilaku, Frekuensi Konsumsi Fast Food, Diet Dan Genetik Dengan Tingkat Kelebihan Berat Badan http://journal.unair.ac.id/download-fullpapersmgif4cfed1d44full.pdf 